\title{
Quelles allégations pour les compléments alimentaires à base de plantes?
}

Ce n'est pas déchoir pour une plante dite médicinale que de figurer comme ingrédient d'un complément alimentaire puisque, répondant à la définition complète de ce dernier, c'est lui reconnaître à la fois un intérêt pour compléter le régime alimentaire normal et des propriétés nutritionnelles ou physiologiques qui contribuent ainsi à notre maintien en bonne santé.

Il y avait bien évidemment un ménage à faire dans des revendications "santé " de ces produits parfois exagérées,

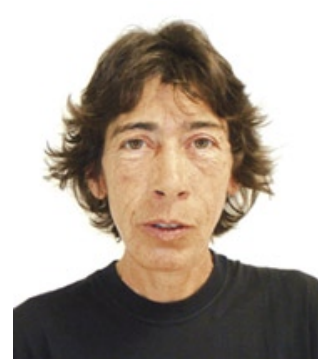
fantaisistes, voire trompeuses ou faisant croire au traitement d'une maladie.

C’est dans ce but qu'a été conçu le règlement européen 1924-2006; il prévoit Gre des allégations santé soient attachées à un nutriment (vitamine ou élément minéral), à une substance ou à une plante : rôle dans la croissance, le développement et les fonctions de l'organisme, rôle dans les fonctions psychologiques et comportementales, aide au contrôle du poids ; allégations relatives au développement et à la santé de l'enfant, à la réduction d'un risque de maladie. En revanche, toute allusion à la prévention ou au traitement d'une maladie est interdite.

Après une longue phase préparatoire, ce travail de validation est enfin en cours, mais à quel prix!

Un comité d'experts réunis au sein de l'EFSA (European Food Safety Authority) udie actuellement les demandes d'allégations faites par des industriels et par des représentants légaux de chaque pays (en France, la DGCCRF) ${ }^{1}$. Et ces experts ne reconnaissent pas à ce jour l'usage traditionnel des plantes; les monographies, la pharmacopée ne sont pas à leurs yeux des preuves suffisantes d'activité alors qu'elles en sont pour les plantes et parfois les mêmes, entrant dans la composition des médicaments de phytothérapie. Deux poids, deux mesures ? Ces experts demandent des études cliniques, mais des études cliniques réalisées sur une population générale : par exemple, prouver l'intérêt d'une plante pour maintenir ses articulaions en bonne santé chez des gens qui n'en souffrent pas encore. C'est donc ainsi quje la commission de l'EFSA estime non fondé l'intérêt de la reine des prés, du gingembre, de l'insaponifiable d'avocat, du bouleau, du peuplier, du curcuma, de l'ortie ou encore du saule dans le confort articulaire.

${ }^{1}$ Direction générale de la concurrence, de la consommation et de la répression des fraudes 
Et que dire du pouvoir antioxydant des plantes? Toujours selon le comité d'experts, rien ne permet de revendiquer le fait qu'avoir des propriétés antioxydantes soit un effet physiologique bénéfique ; prétendre protéger les cellules du vieillissement prématuré est impossible puisqu'il n'existe pas de définition ou de description du vieillissement prématuré lié à l'oxydation ; protéger les lipides ou l'ADN de l'oxydation, oui, c'est un effet bénéfique. Mais là encore, les études in vitro ou chez l'animal ne préjugent en rien de ce qui peut se passer chez l'homme, et il n'y aurait pas d'étude clinique reliant la consommation d'un aliment à la protection des cellules humaines, des lipides, de l'ADN ou des protéines contre les altérations dues au stress oxydatif : donc pas d'action antioxydante pour les baies (myrtille, cassis, canneberge, airelle), la grenade, le ginkgo, l'écorce de pin des Landes, le resvératrol, le sulphoraphane, le thym, le romarin, l'origan, le rooibos, le maté, l'acérola, le chardon-marie, le curcuma, le thé vert, l'extrait de pépins de raisin ou le raisin lui-même.

Il ne peut pas être revendiqué non plus, toujours selon ces experts, un intérêt au thé vert dans le contrôle de la plaque dentaire, l'entretien des os, le maintien d'une cholestérolémie et d'une pression artérielle normales; les études chez l'homme seraient insuffisantes, voire inexistantes. Même aux pruneaux, il n'est pas reconnu de relation entre leur consommation et le maintien d'un transit normal.

De tout temps, l'homme a utilisé des plantes pour rester en bonne santé : ail, sauge, pissenlit, romarin, canneberge, thé vert, menthe poivrée, mélisse, myrtille, cannelle, etc. D’ailleurs, l'European Botanical Forum écrit : "les plantes peuvent avoir différents effets sur le corps. Dans certains cas, les effets sont thérapeutiques et préconisés pour le traitement de maladies. Dans d'autres cas, les effets contribuent à

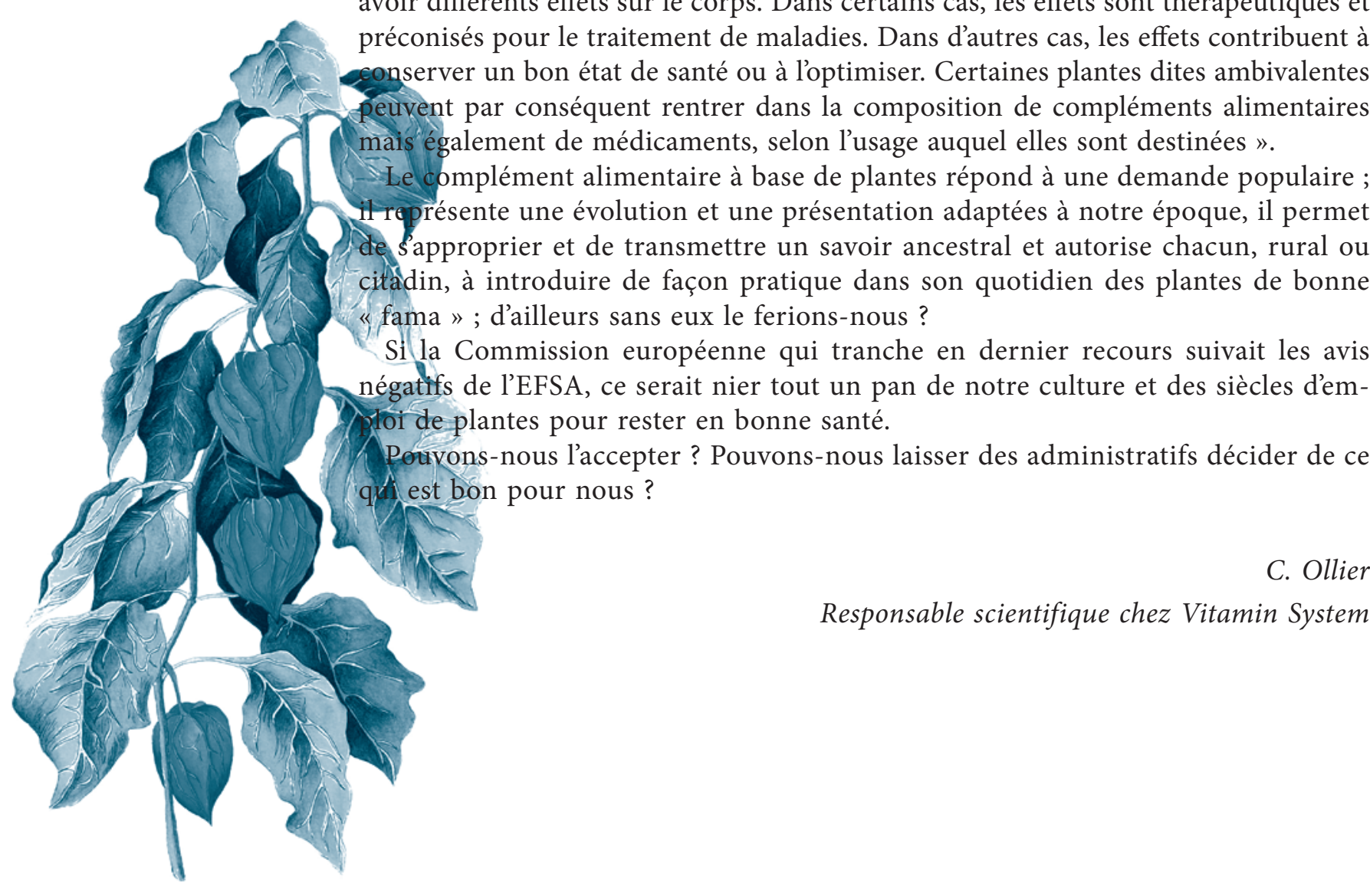

